\title{
VÍNCULOS SOCIO-ESPACIALES Y GOBERNANZA LOCAL: APEGO AL LUGAR Y PARTICIPACIÓN EN LA INICIATIVA BOSQUE MODELO PALENCIA
}

\author{
Fátima Cruz \\ Departamento de Psicología e Instituto U. de Investigación Forestal Sostenible (IUFor) - Universidad de Valladolid. \\ Campus de la Yutera (Palencia) \\ fcruz@psi.uva.es \\ ORCID iD: https://orcid.org/0000-0003-1634-8266 \\ Andrea García-Bengochea \\ Departamento de Psicología de la Universidad de Valladolid. Campus de la Yutera (Palencia) \\ andreagarciabengochea@gmail.com \\ ORCID iD: https://orcid.org/0000-0003-4017-5414
}

Recibido: 20/01/2020; Aceptado: 05/08/2020

Cómo citar este artículo / Citation: Cruz, Fátima y García Bengochea, Andrea (2020). Vínculos socio-espaciales y gobernanza local: Apego al lugar y participación en la iniciativa Bosque Modelo Palencia. Estudios Geográficos, 81 (289), e048. https://doi.org/10.3989/ estgeogr.202062.062

RESUMEN: Este estudio tiene como objetivos analizar cómo los vínculos afectivos entre las personas y los lugares pueden influir en la sostenibilidad rural y de qué manera la participación en iniciativas colectivas de gobernanza local con enfoque paisaje pueden fortalecer el apego al lugar en el medio rural. En 2015 un grupo de agentes sociales del centro-norte de la provincia de Palencia empezó a reunirse para identificar las problemáticas locales y elaborar propuestas colectivas para la sostenibilidad rural. Como resultado de ese proceso, en 2017 crearon la Asociación Bosque Modelo Palencia, que constituye el presente caso de estudio. La investigación se llevó a cabo con metodología cualitativa y la realización de 16 entrevistas en profundidad a miembros de la junta directiva de la asociación y personas directamente implicadas en los procesos de dinamización del territorio estudiado. Del análisis de las entrevistas, realizado con procedimientos de codificación y categorización propios del tratamiento de datos cualitativos, destacamos en este artículo dos categorías temáticas: las referencias de identidad de lugar y la participación y vínculo con el lugar. Los resultados muestran que, además de razones socio-económicas, la despoblación del medio rural y los procesos de arraigo tienen relación con procesos subjetivos y que los significados atribuidos a la ruralidad influyen en el apego al lugar. Por otro lado, se observa que las personas más implicadas en iniciativas de gobernanza local presentan fuertes vínculos con el lugar, que se retroalimentan en las dinámicas colectivas. Dichos vínculos tienen relación con valoraciones positivas de la ruralidad y refuerzan la decisión de permanecer en el territorio.

PALABRAS CLAVE: Apego al lugar, Bosque Modelo, psicología socio-ambiental, significados de lugar, sostenibilidad social.

\section{SOCIO-SPATIAL BONDS AND LOCAL GOVERNANCE: PLACE ATTACHMENT AND PARTICIPATION WITHIN THE PALENCIA MODEL FOREST INITIATIVE}

ABSTRACT: This study aims to analyze how the affective bonds developed between people and places can influence rural sustainability, as well as how participation in collective initiatives of local governance or Landscape Approach can lead people to build bonds with rural territories and strengthening the desire to remain living there. In 2015, a group of multisector and multilevel stakeholders started working for local governance and sustainability in the center-north of the Palencia province. The Palencia Model Forest Association was created in 2017, in order to develop collective proposals for local revitalization. A qualitative research with case study method was carried on. We conducted 16 stakeholders' in-depth interviews. Using qualitative data analysis, two main thematic categories emerged from the interviews: references of place identity and participation linking with the place. The results show that, in addition to socio-economic reasons, subjective processes are key in the rural depopulation. Meanings of rurality work for or against of place attachment as well. People involved in local governance initiatives show strong bonds with the place, where collective dynamics reinforce them with rural positive assessments. It influences the decision to remain living in the rural place.

KEYWORDS: Place attachment, Model Forest, socio-environmental psychology, place meanings, social sustainability.

Copyright: (C) 2020 CSIC. Este es un artículo de acceso abierto distribuido bajo los términos de la licencia de uso y distribución Creative Commons Reconocimiento 4.0 Internacional (CC BY 4.0). 


\section{INTRODUCCIÓN}

La despoblación del medio rural viene ganando espacio en los debates públicos y en la agenda política en los últimos años, al tiempo en que crece la preocupación por los temas ambientales y por la relación entre cambio climático y sostenibilidad de los territorios rurales (Angelstam et al., 2013b; Angelstam et al., 2019a; Axelsson, Angelstam, Elbakidze, Stryamets, y Johansson, 2011). Desde inicios del siglo XX, las áreas rurales en todo el mundo se han visto sometidas a un proceso de transformación de modelos productivos y de globalización económica, con un dominio de los estilos de producción y consumo urbano-industriales. Desde entonces, se vienen produciendo grandes movimientos migratorios y desequilibrios demográficos importantes al nivel mundial. En todo el territorio español y en particular en algunas Comunidades Autónomas como Castilla y León, estos desequilibrios vienen siendo especialmente acusados (Camarero et al., 2009; CES, 2012). Según el documento de trabajo de la Comisión de Despoblación de la Federación Española de Municipios y Provincias (FEMP, 2017), "la brecha demográfica entre el medio rural y el urbano volvió a agrandarse en 2015... El resultado ha sido que se ha agravado el desequilibrio territorial: más peso demográfico de las grandes ciudades en detrimento del medio rural" (p. 9). La brecha sigue ampliándose en todo el mundo en esa misma dirección. Según datos de Naciones Unidas, hay una creciente concentración de población en las ciudades y la población rural mundial disminuye, a la vez que envejece. Según las proyecciones de este organismo, se prevé que solamente un $12 \%$ de la población en España siga viviendo en el medio rural en el año 2050 (United Nations, 2018).

Las políticas dirigidas al medio rural puestas en marcha en las últimas tres décadas partieron de la concepción de que el problema del abandono del medio rural tiene sus raíces principalmente en cuestiones económicas, como se evidencia, por ejemplo, en los objetivos marcados por los organismos oficiales para las iniciativas de desarrollo rural, en las acciones subvencionables y en los indicadores de evaluación predominantemente económicos que son utilizados (inversiones, no de empleos y de empresas creados, etc.). Afirma Esparcia (2003), refiriéndose a la Iniciativa Comunitaria LEADER II (1996-2001), que "las inversiones suelen utilizarse como indicadores fundamentales a la hora de valorar las consecuciones de la Iniciativa" (p.8). Es indudable que las iniciativas de desarrollo rural vienen teniendo un significativo im- pacto en el medio rural más allá de aspectos económicos, promoviendo una mayor participación social, fomentando el liderazgo y la capacidad de gestión y avanzando en un enfoque territorial, por lo que han logrado, así, dar visibilidad a la innovación y creatividad en el medio rural (Arabatzis et al., 2010; Cruz et al., 2011; Esparcia, 2003 y 2014; Maurer y Silva, 2014).

Sin embargo, la realidad se muestra tozuda y, como han puesto de manifiesto las propias cifras demográficas (FEMP, 2017) y diversos estudios (Alario Trigueros y Baraja Rodríguez, 2006; Esparcia, 2003; Navarro Valverde, Cejudo García y Maroto Martos, 2012; Nieto Masot y Cárdenas Alonso, 2015), ni las iniciativas de creación de empleo, ni las propuestas de diversificación de las actividades productivas han sido suficientes para revertir el problema de la despoblación y abandono del medio rural. La continua pérdida de población debería obligar a los actores sociales a repensar estrategias y políticas para la sostenibilidad del medio rural y a poner más énfasis en la reproducción de la vida social de las áreas rurales (Camarero et al. 2009; Cruz, 2006). Creer que el problema de la despoblación deriva solo de la falta de empleo y del recorte de servicios es desconocer la complejidad del problema. Sin infravalorar la importancia que tiene la situación económica local y personal y el papel que juega el acceso a servicios dignos en los territorios rurales, es necesario reconocer, tal como propone Guattari (1996), los procesos subjetivos que están operando en la construcción de vínculos socioespaciales y su incidencia en la sostenibilidad socioambiental. Así, este trabajo procura analizar los lazos socio-afectivos desarrollados hacia un territorio por personas que participan en procesos colectivos de gobernanza local para la sostenibilidad socio-ambiental y las explicaciones que estas ofrecen sobre el proceso de despoblación rural provocado por la migración hacia entornos urbanos.

En los últimos años, han surgido nuevas iniciativas colectivas relacionadas no solo con el desarrollo de actividades productivas, más propias del desarrollo rural, sino desde una comprensión de los territorios como sistemas socio-culturales y ecológicos. Dichas iniciativas surgen vinculadas a redes y organizaciones internacionales, tales como, Reservas de la Biosfera, Geoparques de la UNESCO y Red Internacional de Bosques Modelo, entre otras. Son estructuras y procesos que buscan promover la sostenibilidad y la dinamización de amplios territorios rurales (Angelstam et al., 2019b), implicando alianzas entre personas e 
instituciones, tanto rurales como urbanas, de sectores diversos y a diferentes niveles administrativos (local, regional, nacional e internacional). Sobre todo, están promoviendo procesos participativos con toma de decisiones que impliquen a las personas y agentes sociales en la búsqueda de soluciones alternativas a las dificultades, identificadas por los propios interesados, relacionados con los recursos naturales en un territorio determinado.

Este enfoque de gobernanza local, multisectorial y multinivel, que se viene denominando internacionalmente como 'enfoque paisaje' (landscape approach), pone el énfasis en la relación de las comunidades y personas con la biodiversidad y los recursos naturales, su preservación, gestión y aprovechamiento económico, cuidando el equilibrio socio-ecosistémico (Angelstam et al., 2013a; Angelstam et al., 2019a). Se fundamenta básicamente en una comprensión socioecológica de los problemas locales, conjugando diferentes perspectivas en un enfoque transdisciplinar desde la complejidad, que no fragmenta la realidad entre aspectos económicos, ambientales y sociales, sino que procura conjugar singularidad y multiplicidad (Morin, 1994). El enfoque paisaje se desarrolló como concepto a partir de un entendimiento de que las soluciones sostenibles para la conservación ambiental requieren necesariamente de la participación de las personas que viven en el territorio y de que estas son conocedoras de su propia realidad e interlocutoras válidas para participar en las decisiones junto con representantes de diferentes niveles de las administraciones públicas (Axelsson, 2009; Axelsson et al., 2011). Según Axelsson et al. (2011) el enfoque paisaje se define como "un proceso de aprendizaje social en el que los interesados desarrollan e implementan soluciones de gestión a través de un proceso participativo de toma de decisiones" (p. 18). Así, considerando que el enfoque paisaje consiste en una acción directa y colectivamente organizada de las personas y agentes sociales para transformar el territorio que habitan a través de procesos de gobernanza local, parece importante estudiar su incidencia en la construcción de vínculos socio-espaciales y de apego a un territorio concreto.

Los estudios de psicología ambiental (Horlings, 2016; Manzo y Perkins, 2006; Vidal y Pol, 2005) muestran que los vínculos afectivos desarrollados entre las personas y los lugares se construyen a través de la participación de las personas y las comunidades en los procesos de transformación de su entorno espacial. Acercar lo más posible ese territorio vivido a un horizonte deseable desde un punto de vista personal y comunitario promueve el proceso de apropiación del espacio (Vidal y Pol, 2005). Para Pol (1996) el término 'apropiación del espacio' designa el proceso por el cual las personas dotan de significado a los entornos y los transforman en lugares; lugares con los que se identifican y cuyas cualidades se atribuyen como propias, configurando su identidad personal y social. Vidal y Pol (2005) consideran "que la apropiación del espacio, a través de la identificación y la acción en el entorno explican el apego al mismo" (p.292). Ello, a su vez, nos permite comprender mejor acerca de cómo se produce la vinculación entre las personas y los lugares.

A la hora de analizar los lazos afectivos entre las personas y los lugares, varios autores distinguen dos planos de vinculación con el lugar (Hidalgo, 2013; Scannell y Gifford, 2010): uno físico y otro social, que implican modos distintos e interrelacionados de vincularse con el lugar. El social se refiere a los sentimientos que las personas desarrollan hacia las otras personas y grupos que configuran el contexto social en un determinado lugar y el plano físico implica los sentimientos que las personas desarrollan hacia las características físicas de los lugares (Hidalgo, 2013; Hidalgo y Hernández, 2001). Así, según Vidal et al., (2013) "las personas se apegan a los lugares por las relaciones sociales que estos facilitan y por las comodidades y recursos que los espacios proveen" (p. 278).

De esta manera, los vínculos que se generan entre los espacios físicos y las personas implican la transformación de un territorio cualquiera en un lugar "propio". Ried Luci (2015) define lugar como "un territorio dotado de identidad que contribuye a su vez a la construcción de la identidad del lugar y de las personas" (p.219), es decir, un espacio material y físicamente disponible para las personas que está cargado de significados simbólicos (Vidal y Pol, 2005). Un lugar es, según el geógrafo, un territorio vivido y un territorio de vivencias, que configura así el propio espacio subjetivo de las personas que lo habitan. Así pues, los espacios físicos se convierten en lugares gracias a la experiencia y la acción de las personas que participan en ellos, cargándolos de significados y contenidos subjetivos, tales como atribuciones, valores, evocaciones y recuerdos. Los lugares son construidos por las personas en la interacción social (Mendoza y Bartolo, 2012). Las experiencias significativas de las personas en los lugares se acumulan y suscitan recuerdos sobre quiénes son y de dónde vienen, implicando emociones y confirmando su propia identi- 
dad, individual y colectiva (Pinto de Carvalho y Cornejo, 2018). En palabras de Ramos de Robles y Feira Cuevas (2016), el lugar "refleja y acumula las huellas de las distintas generaciones que lo han habitado y transformado: es un legado histórico/emotivo" (p.85).

El apego al lugar nos parece un concepto especialmente relevante para indagar en el problema de la despoblación y facilitar la comprensión sobre la construcción de los vínculos con los territorios rurales. Además, los estudios realizados con ese concepto se desarrollaron casi exclusivamente en el ámbito urbano y pocos exploran su relación con la sostenibilidad local (Grenni, Soini y Horlings, 2019), por lo que su novedosa aplicación en estudios rurales es todavía más relevante.

Según Pinto de Carvalho y Cornejo (2018), el apego al lugar constituye una relación afectiva/simbólica entre las personas y los lugares, capaz de generar identidad personal y territorial. Es decir, se genera un vínculo que influye en cómo las personas se perciben a sí mismas y construyen su autopercepción en relación con un espacio físico cargado de significados para ellas (Mendoza y Bartolo, 2012). Esta capacidad de experimentar y compartir con otras personas sentimientos y sensaciones hacia determinados lugares permite el desarrollo de los vínculos de pertenencia y apego (Ramos de Robles y Feira Cuevas, 2016). El espacio empieza, por lo tanto, a adquirir sentido cuando a través de la experiencia personal y colectiva es dotado de significados y atribuciones emocionales y simbólicas (Ried Luci, Le Bon, Lobo y Henriquéz, 2018). Parece también importante destacar que la conexión grupal con el lugar se genera gracias a la participación de las personas en actividades colectivas (Berroeta, Vidal y Di Masso, 2016). Así como, en el sentido opuesto, la vinculación con el lugar parece promover la participación en los procesos comunitarios (Davies, 2001; Horlings, 2016; Manzo y Perkins, 2006).

El concepto de apego al lugar (Lewicka, 2011), además, tal y como se identificó en las teorías del apego interpersonal (Scannell y Gifford, 2014), implica la tendencia de las personas a procurar permanecer cerca del objeto de apego. Según Hidalgo y Hernández (2001), el apego al lugar es entendido como "un lazo afectivo que las personas desarrollan hacia determinados lugares en los que tienden a permanecer, sentirse cómodas y seguras" (p. 274), además de caracterizarse por "la tendencia a lograr y mantener un cierto grado de proximidad con el objeto de apego" (Hidalgo, 1998; p.51). Este es un aspecto especialmente relevante en la utilización de este concepto en los estudios para la comprensión de los procesos de despoblación de los territorios rurales.

En ese sentido, en la presente investigación hemos explorado el papel de los procesos intersubjetivos que tienen lugar con la participación colectiva en iniciativas de gobernanza local con enfoque paisaje. En ellas las personas participantes construyen y/o renegocian los significados compartidos atribuidos al territorio vivido, a la vez que, sobre ese territorio se trabaja conjuntamente para, transformándolo, acercarlo al horizonte colectivamente deseado. Planteamos que los procesos intersubjetivos juegan un importante papel en la construcción de los vínculos con el territorio y en la apropiación del espacio rural.

Berroeta, Ramoneda, Rodríguez, Di Masso y Vidal (2015) afirman que el apego al lugar y el sentido de comunidad influyen directamente en la revitalización de los vecindarios, puesto que la vinculación con el lugar se encuentra relacionada con la participación de las personas en los procesos de transformación de su comunidad. Si no existe conexión emocional entre las personas y los lugares, estas no suelen comprometerse en la puesta en marcha de iniciativas destinadas a la mejora del medio que habitan. En el mismo sentido, Escalera (2013) señala que "el sentimiento de pertenencia de la población con respecto al territorio del que forma parte es el factor clave sobre el que se sustenta la implicación de dicha población con respecto a las acciones sobre el mismo" (p.338). Este sentimiento de afiliación a un entorno concreto implica, a su vez, formar parte de un grupo de personas con el que, probablemente, se comparten ciertos códigos, rasgos y señas identitarias que han sido elaboradas en la interacción social y atribuidas como propias a través de procesos de adscripción y diferenciación grupal (Mendoza y Bartolo, 2012).

Así, se entiende que los procesos de gobernanza local con enfoque paisaje puedan estar favoreciendo que las personas desarrollen vínculos afectivos con el lugar en el territorio en el que participan. Hay que considerar que los procesos intersubjetivos hacen referencia a compartir las características y cualidades atribuidas a un lugar significativo en el que los individuos interactúan y tienen experiencias en el marco de su cotidianidad, facilitando que se identifiquen colectivamente con ese lugar al que sienten que pertenecen.

Sin embargo, estudios anteriores (Cruz, 2006) muestran que una valoración positiva o negativa construida acerca de lo rural y lo urbano interviene en la elabo- 
ración de las identidades sociales y personales y puede influir en el deseo de permanencia en ese contexto, que contiene sus referencias de identidad de lugar. Por ello, una valoración social negativa de la ruralidad puede estar fomentando la construcción de significados de lugar que dificulten los procesos subjetivos de apego al medio rural y fomenten procesos migratorios. Desde una idealización de lo urbano, la movilidad territorial se presentó como una posibilidad para que la población rural cambiase su pertenencia grupal en la búsqueda de una identidad social simbólicamente más positiva y poderosa (Cruz, 2006).

En las últimas décadas, las iniciativas de gobernanza local y las nuevas funciones asociadas al medio rural, que ponen de relieve el aprovechamiento de recursos endógenos y la conservación del patrimonio, tanto cultural como natural, han favorecido, por un lado, la diversificación de la economía, pero también el fortalecimiento de la identidad y los rasgos culturales propios del lugar (Rodríguez-Chaves y Solís-Rosales, 2016). Los nuevos significados atribuidos a la ruralidad, que valorizan criterios de calidad de vida y la proximidad con la naturaleza, el tiempo de ocio y la tranquilidad, están cuestionando el ideal urbano como modelo hegemónico de referencia e impulsando una cierta revalorización de los territorios rurales (Camarero et al., 2009; Cruz, 2006). Desde esa perspectiva, las iniciativas de gobernanza local con enfoque paisaje, a partir de procesos colectivos de aprendizaje y toma de decisiones (Axelsson et al., 2011), plantean estrategias basadas en la gestión y uso sostenible de los recursos naturales y culturales propios de cada territorio. Sobre todo, la búsqueda de estrategias asociativas y participativas multisectoriales y que implican diferentes niveles de la administración pública, pueden estar contribuyendo a la sostenibilidad rural. Dichas iniciativas procuran generar dinamismo y empoderamiento de los territorios, no solo desde una perspectiva económica, sino como generadoras de procesos colectivos de innovación social y fortalecedoras de las redes comunitarias (Bock, 2016; Esparcia, 2014; Marcy y Mumford, 2007; Maurer y Silva, 2014; Neumeier, 2012 y 2017), que vienen favoreciendo una valoración más positiva de lo rural y parecen promover el deseo de permanencia en los territorios.

Así, estos planteamientos sobre vinculación socioespacial y apego al lugar adquieren un nuevo sentido en el estudio de la despoblación del medio rural, ya que la vinculación emocional con un territorio de las personas participantes en experiencias de gobernan- za local con enfoque paisaje puede aportar evidencias empíricas claves sobre sostenibilidad social. Y se plasman en la presente investigación cualitativa a través de un estudio de caso con el objetivo de analizar el apego al lugar desarrollado por personas que participan en iniciativas de gobernanza local destinadas a revitalizar y dinamizar contextos rurales con recursos socio-culturales y naturales singulares. El caso de estudio seleccionado es la Asociación Bosque Modelo Palencia, creada en 2017 por un grupo de agentes sociales del centro-norte de esta provincia, con el propósito de identificar las problemáticas locales y elaborar propuestas colectivas para la sostenibilidad rural. Actualmente, esta es la única iniciativa en España que forma parte de la Red Internacional de Bosques Modelo y de la Red Mediterránea de Bosques Modelo. En el estudio se analiza, a través del discurso de personas participantes, los elementos que ellas destacan como vinculantes a ese territorio específico y cómo estos aparecen configurando el apego al lugar y la decisión de establecer sus proyectos vitales y/o laborales en el medio rural.

\section{Metodología y ÁREA de estudio}

En esta investigación se ha empleado metodología cualitativa, procurando construir una comprensión profunda del fenómeno estudiado (Flick, 2004) y asumiendo la subjetividad como parte inalienable de la realidad social y una dimensión constitutiva de la sostenibilidad (Guattari, 1996). Exploramos los vínculos que las personas están desarrollando en su vida cotidiana con el territorio rural y las valoraciones de la ruralidad que manifiestan en sus discursos sobre el mismo. A partir del discurso construido sobre las experiencias personales de habitar en el medio rural y de participar en procesos de gobernanza local se analiza el apego al lugar (Bailey, Devine-Wright y Batel, 2016; Di Masso, Dixon y Durrheim, 2013) en una iniciativa colectiva de enfoque paisaje.

La investigación se desarrolló con el método de estudio de caso (Stake, 2005) en la perspectiva de profundizar en las particularidades de un contexto rural concreto, en el cual las personas participantes desarrollan sus actividades cotidianas y dotan de significado el lugar en el que viven en interacción con otros significantes. Para alcanzar los objetivos planteados se eligió como caso de estudio a la Iniciativa Bosque Modelo Palencia (BMP), por ser una experiencia novedosa de enfoque paisaje como único Bosque Modelo en España, de los 60 que hay actual- 
mente en el mundo. Según la Red Internacional de Bosques Modelo (IMFN, 2008), un bosque modelo es una "asociación voluntaria de personas que viven en un territorio, o se interesan por él, para descubrir, definir, fomentar y garantizar su sostenibilidad; y que al compartir sus experiencias y conocimientos contribuyen a alcanzar objetivos ambientales a escala local y mundial".

El Bosque Modelo Palencia (BMP) fue promovido a partir del proceso participativo generado con el proyecto europeo de investigación SIMWOOD (Sustainable Innovative Mobilisation of Wood, 7FP-KBBE, no 613762), que se llevó a cabo desde el IUFOR- Instituto Universitario de Investigación en Gestión Forestal Sostenible, entre los años 2015 y 2017 en Castilla y León. En 2017, después de un período de reuniones y grupos de trabajo para la realización de un diagnóstico participativo y la definición de líneas de trabajo para promover la sostenibilidad local, se creó la Asociación Bosque Modelo Palencia (https:// palenciabosquemodelo.es/). En la asociación participan ayuntamientos, juntas vecinales, empresas del territorio, fundaciones, asociaciones y personas individuales, contando también con el apoyo de la Diputación de Palencia, de la Junta de Castilla y León y de la Universidad de Valladolid. El Bosque Modelo Palencia forma parte de la Red Internacional de Bosques Modelo (https://imfn.net/) y de la Red Mediterránea de Bosques Modelo (https://www.medmodelforest. net/es/). Su territorio se ubica en la provincia de Palencia, entre el Camino de Santiago como límite sur y el Parque Natural de la Montaña Palentina al norte, dando idea de la riqueza de los recursos naturales, histórico-artísticos y turísticos que configura ese espacio. Tiene una extensión total de 4.067,48 km2, lo que corresponde al $42,95 \%$ de la superficie total de la provincia, comprendiendo 92 municipios con menos de 43.000 habitantes distribuidos de manera muy desigual. Más del $80 \%$ de los habitantes se concentran en seis núcleos de población, que tienen entre 1.500 y 7.000 habitantes, mientras el $20 \%$ de la población restante se distribuye entre más de 300 pueblos dispersos. La despoblación rural y la falta de relevo generacional fueron los principales problemas locales señalados durante el proceso de creación del BMP y de elaboración de un plan estratégico de acción en el territorio (véase una descripción más detallada en Cruz, 2019).

En el estudio de caso se emplearon entrevistas en profundidad semiestructuradas, con preguntas dirigidas y abiertas para capturar directamente el discurso de las personas participantes en el caso estudiado. Según Flick (2004), las entrevistas semiestructuradas son muy utilizadas porque "es más probable que los sujetos entrevistados expresen sus puntos de vista en una situación de entrevista diseñada de manera relativamente abierta que en una entrevista estandarizada o un cuestionario" (p.89). El tiempo de duración de las entrevistas no estaba limitado y dependía del diálogo establecido en cada una de ellas, con un resultado de entre 30 y 48 minutos.

Para operacionalizar la realización de las entrevistas se diseñó un guion previo, de modo a garantizar la posibilidad de establecer interrelaciones entre los contenidos de las diversas entrevistas durante el proceso de análisis de datos, pero con amplio margen para establecer un diálogo fluido con cada persona entrevistada. El guion previo contemplaba una parte de presentación personal y de la situación familiar y laboral de la persona entrevistada y 11 preguntas dirigidas a promover un diálogo en torno a cuatro bloques temáticos: 1) valoración personal del lugar en el que vive - casa/hogar y territorio, descripción de la vinculación afectiva con el lugar y los elementos físicos y sociales del entorno; 2) valoración de la vida en el medio rural y relación con lo urbano; 3) participación en grupos y asociaciones de la zona y descripción de las actividades realizadas habitualmente; y 4) participación en la iniciativa Bosque Modelo Palencia: motivaciones iniciales, motivaciones e intereses de los y las participantes, aportaciones de la iniciativa al territorio y perspectivas de futuro.

Una investigación cualitativa no busca resultados generalizables, ni la muestra empleada pretende ser representativa. Lo que se busca en este estudio es una comprensión profunda de cómo la participación en una iniciativa de gobernanza local puede incidir en el apego al lugar en el Bosque Modelo Palencia recogiendo perspectivas diversas en las voces de sus protagonistas. Así, se realizó un total de 16 entrevistas especialmente seleccionadas para atender a los objetivos del estudio. Se entrevistó a siete mujeres y nueve hombres, con edades comprendidas entre 25 y 51 años, entre marzo de 2017 y diciembre de 2019. En 2017, año de constitución de la Asociación Bosque Modelo, se realizaron las primeras diez entrevistas y en 2019 se realizaron las últimas seis entrevistas para recoger datos complementarios o cambios significativos en los discursos de personas implicadas en el caso de estudio con el paso de dos años de existencia de la asociación y posibilitar una triangulación (Stake, 2005) de los datos obtenidos en el primer año. La 
realización de entrevistas terminó con la saturación teórica (Flick, 2004). La selección de participantes se realizó atendiendo a la diversidad de perfiles de agentes sociales que forman parte de la iniciativa y por su nivel de implicación en las actividades realizadas en el caso estudiado. Así, se entrevistó al $60 \%$ de la junta directiva de la Asociación Bosque Modelo Palencia, siete de sus once componentes, y a otras nueve personas que, no formando parte de la dirección, tienen un alto nivel de liderazgo en los procesos y actividades llevados a cabo.

Las entrevistas fueron grabadas y transcritas para su posterior análisis y codificación. Los datos obtenidos han sido analizados mediante codificación y categorización del discurso de los participantes (Flick, 2004; Stake, 2005). El proceso de análisis se realizó generando categorías temáticas para organizar e interpretar los significados que se otorgan a los procesos de vinculación con el territorio y el apego de la población al medio rural a partir de la participación en la gobernanza local. El análisis cualitativo de los datos se ha llevado a cabo utilizando el programa informático RQDA, que es un paquete de $\mathrm{R}$ para analizar textos cualitativos (Huang, 2016).

\section{Resultados}

Diversos estudios muestran que las cualidades asignadas al lugar, en cuanto territorio dotado de significaciones y relevancia subjetiva, son atribuidas como propias por las personas que a él se vinculan, contribuyendo a definir su identidad personal y grupal (Ried Luci, 2015; Vidal et al., 2013) y motivando su permanencia en ese lugar donde se sienten cómodas y seguras y donde pueden preservar y compartir su cultura (Hidalgo y Hernández, 2001; Vidal et al., 2013). Los resultados encontrados indican que los significados expresados inciden en las vivencias emocionales, potenciando o dificultando el sentimiento de pertenencia y el desarrollo del apego al lugar.

Del análisis de los datos, destacan dos categorías temáticas principales relacionadas con los procesos de apego al lugar en el territorio estudiado. La primera, denominada como referencias de identidad de lugar, incluye las subcategorías: significado de lugar y sentimiento de pertenencia. A su vez, la segunda categoría se denominó como participación y vínculo con el lugar, con dos subcategorías: dinamización del territorio y reconocimiento de una comarca.

TABLA 1

PERFILES DE PARTICIPANTES EN EL ESTUDIO

\begin{tabular}{|c|c|c|c|c|}
\hline ID & EDAD & GÉNERO & LOCALIDAD (habitantes) & ÁMBITO DE ACTUACIÓN \\
\hline E.1 & 35 & Mujer & $<3000$ & Educación primaria \\
\hline E.2 & 51 & Hombre & $<3000$ & Representante Político \\
\hline E.3 & 51 & Mujer & $<500$ & Asociación de Mujeres y empresa de alimentación \\
\hline E.4 & 46 & Hombre & $<3000$ & Grupo de Acción Local - Desarrollo rural \\
\hline E.5 & 38 & Mujer & $<500$ & Empresa de Ingeniería ambiental \\
\hline E.6 & 36 & Mujer & $<100$ & Representante Política \\
\hline E.7 & 30 & Hombre & $<100$ & Asociación y empresa de educación ambiental \\
\hline E.8 & 39 & Hombre & $<3000$ & Empresa de tecnología agraria \\
\hline E.9 & 42 & Hombre & $<3000$ & Empresa de ingeniería ambiental \\
\hline E.10 & 49 & Hombre & $<3000$ & Gestión Forestal - Junta de Castilla y León \\
\hline E.11 & 31 & Mujer & $<2000$ & Educación Social \\
\hline E.12 & 26 & Hombre & $<500$ & Sector turístico \\
\hline E.13 & 25 & Mujer & $<500$ & Asociación joven \\
\hline E.14 & 28 & Mujer & $<500$ & Asociación joven \\
\hline E.15 & 42 & Hombre & $<500$ & Empresa de Ingeniería Forestal \\
\hline E.16 & 41 & Hombre & $<500$ & Asociación cultural y Empresa de Ingeniería Forestal \\
\hline
\end{tabular}

Fuente: Elaboración propia. 


\subsection{Referencias de identidad de lugar}

Los significados atribuidos a la ruralidad implican valoraciones positivas y/o negativas del medio rural que parecen estar influyendo en la construcción de los vínculos afectivos con estos entornos, así como, en la elaboración de la identidad personal y grupal de los habitantes rurales (Cruz, 2006). Los significados se relacionan, a su vez, con el concepto de identidad de lugar, proceso mediante el cual las personas y los grupos incorporan a su autoconcepto cualidades ambientales que contribuyen a definir su identidad (Vidal y Pol, 2005). La elaboración de estos significados se estaría llevando a cabo a través de los conocimientos, las creencias y los sentidos que las personas asocian a un espacio determinado y que facilitan su vinculación a ese lugar (Scannell y Gifford, 2010).

Considerando que estudios anteriores (Cruz, 2006) muestran factores psicosociales que pueden estar influyendo en la despoblación del medio rural y concentración de población en las ciudades, parece necesario indagar sobre el papel que los significados asociados a la ruralidad están teniendo en la elaboración de la identidad grupal de los habitantes rurales $y$ en el desarrollo del sentimiento de pertenencia en la actualidad. Los resultados obtenidos reflejan que las personas entrevistadas señalan significados relacionados con una valoración negativa de la ruralidad que, más allá de cuestiones económicas, perciben estar frenando la permanencia o el asentamiento de población en el medio rural. Sin embargo, ellas mismas atribuyen valoraciones muy positivas al territorio por el que muestran una fuerte vinculación emocional y un fuerte compromiso con la promoción de la sostenibilidad y la construcción de un entorno social y natural deseable para vivir.

\subsubsection{Significados del lugar}

Los significados atribuidos al estilo de vida en el medio rural que afloran en el discurso de las personas entrevistadas reflejan una percepción de bienestar, donde destacan valores como la tranquilidad o la libertad.

"La tranquilidad, sobre todo, y luego, el hecho de no estar encerrado... y aquí abro la puerta y salgo a mi patio y estoy en la calle, pero en mi patio, en mi intimidad. En mi intimidad, pero en naturaleza y en libertad, o sea, yo eso, incalculable el valor, incalculable el valor" (E.6, mujer, 36 años).
La proximidad con la naturaleza y las condiciones ambientales son una constante en los discursos. Por un lado, aparecen valores relacionados con las experiencias vividas en o cerca de la naturaleza, destacando la importancia del entorno físico en los vínculos con el lugar (Hidalgo, 2013; Hidalgo y Hernández, 2001; Scannell y Gifford, 2010) y la intimidad experimentada con la no masificación del medio rural. Por otro lado, el término 'cercanía' se repite en varias entrevistas caracterizando las narrativas sobre las relaciones sociales en los pueblos.

"Yo salgo aquí, conoces a la gente, nunca estás solo, vas a tomar un café a un bar y es que nunca estás solo, porque, como nos conocemos, no te sientes solo..." (E.4, hombre, 46 años)

"Sentirme tranquila, cómoda, el acceso rápido al campo, la cercanía de los vecinos" (E.14, mujer, 28 años)

"Creo que lo que más valoro se describe con la palabra 'cercanía', en sus diversas facetas. Desde la cercanía en un sentido más territorial [...], hasta la cercanía que se genera entre las personas que lo habitan y la tranquilidad y bienestar que genera de alguna manera "conocer" a quién compras el pan y la fruta, quién trabaja en la tienda de enfrente, quién vive en la casa de al lado... (E.11, mujer, 31 años)

De este modo, la "cercanía" define una conexión emocional con vecinos y vecinas, amistades y familiares que es facilitada por esa proximidad física y social que proporciona el entorno rural y parece configurarse como una motivación importante para permanecer en los pueblos y como una seña de identidad del mundo rural. Entre las personas participantes de la investigación, las vivencias, aparentemente satisfactorias que los individuos experimentan y que comparten con otros miembros del grupo, impulsan la creación de significados positivos que favorecen el establecimiento de vínculos afectivos con el territorio e implican el deseo de mantener esa proximidad.

Frecuentemente, aparece una comparación con la vida en las ciudades en contraposición con esa percepción positiva de la ruralidad, principalmente destacando la calidad de vida en los pueblos. Esto está proporcionando una revalorización de los estilos de vida rurales y propiciando una mayor vinculación con estos entornos. Además, se observa que la sostenibilidad empieza a forma parte del discurso de los y las participantes de la iniciativa Bosque Modelo Palencia.

"Hay una cosa que eso es todavía más fundamental, en un pueblo eres alguien, eres alguien, en una ciudad 
no eres nada, no eres nada, [...] formas parte de algo y estás en un entramado..." (E.10, hombre, 49 años).

"Quiero decir, que igual estoy a menos distancia en tiempo de los servicios que alguien que viva en Madrid o Barcelona" (E.16, hombre, 41 años).

"Creo que vivir en un pueblo facilita más seguir un estilo de vida más sostenible que en las ciudades, consumo local, soberanía alimentaria, menos contaminación, mayor contacto con la naturaleza y la tierra, refuerzo de los vínculos humanos..." (E.11, mujer, 31 años).

Además, las personas entrevistadas identifican y ponen enfáticamente de manifiesto cómo una percepción distorsionada y negativa del modo de vida rural, junto con el estigma al que se han visto sometidos sus habitantes, puede haber influido en el abandono de los pueblos y en la dificultad para atraer a nuevos residentes.

"La gente que se ha quedado en los pueblos era porque era lo único que podía hacer, eso se nos ha vendido así, entonces, solo se han quedado los que no podían progresar académicamente. El que valía ha ido a la ciudad y ha ocupado cargos de relevancia" (E.5, mujer, 38 años).

"Desde la ciudad se nos ha visto como los inferiores, o sea, que los que no valíamos para nada nos quedábamos aquí. Entonces eso, eso nos cuesta, esto está en la gente de los pueblos, lo tenemos metido porque lo hemos vivido, entonces eso no nos gusta, eso no nos gusta" (E.4, hombre, 46 años).

Se constata en el discurso de los participantes la percepción de infravaloración de las personas del medio rural por parte de la sociedad urbano-industrial. Esto ha podido dificultar la construcción de una identidad personal y colectiva positiva.

"El gran problema de la despoblación es la mentalidad, que es que la inmensa mayoría de la gente de los pueblos considera que se vive peor en los pueblos que en la ciudad y, por tanto, hace todo lo que puede por vivir en la ciudad" (E.10, hombre, 49 años).

"Yo el problema fundamental que veo es que no nos creemos que vivimos muy bien y, sobre todo, no nos creemos que podemos vivir mejor si estamos amparados, si socialmente nos consideramos fuertes..." (E.5, mujer, 38 años).

Desde esta perspectiva, cabe la posibilidad de que la emigración del campo a la ciudad se configure como una estrategia de movilidad social adoptada por muchos rurales para desvincularse del grupo infravalorado (Cruz, 2006). Además, las evidencias muestran que la interiorización de esas valoraciones negativas esté contribuyendo a la transmisión de un discurso fatalista que estimula la emigración de la juventud y dificulta, por lo tanto, el desarrollo de vínculos afectivos con los pueblos. Explicado en palabras de una de las personas entrevistadas: "Los padres preparan a los hijos para marcharse $y$, además, quieren que se marchen" (E.10, hombre, 49 años).

Asimismo, las personas entrevistadas perciben que la aceptación de este discurso por parte de la sociedad urbana también puede estar frenando el asentamiento de nuevos residentes en el medio rural.

"Yo creo que la gente no va a vivir a los pueblos porque existe un componente social que se lo impide. Tú ahora mismo le dices a tu madre, o a tu padre, o a tu tutor, me quiero ir a un pueblo y dice, 'pero cómo hombre, pero ¿cómo vas a ir a un pueblo, con todo lo que te ofrece XXX (una ciudad)? No hay nadie que te anime, no hay nadie. En el pueblo, a lo mejor tampoco, pero en la ciudad y todo tu entorno, nadie te va a animar." (E.5, mujer, 38 años)

Por otro lado, también aparecen en los significados un rural que expulsa a sus habitantes y las ciudades como espacio de oportunidades. Se destaca de la ciudad las oportunidades formativas y laborales, mientras en el medio rural continúan siendo percibidas por muchos como un limitante para el arraigo, tal como exponían. Se observa un discurso contradictorio entre oportunidades y limitaciones, que se manifiesta entre el querer quedarse y tener que marcharse. Eso aparece principalmente en relación al empleo y oportunidades laborales en el medio rural. Algunos destacan que las limitaciones laborales existentes se sobreponen a los vínculos afectivos con el lugar, otros, más optimistas, destacan las nuevas empresas o posibilidades que se están abriendo en la zona.

"Muchas veces, en muchos casos ¿la gente joven se va por qué? No porque se quiera ir, sino porque no hay opciones" (E.9, hombre, 42 años).

"Yo estoy aquí porque me gusta, por el arraigo familiar, sentimental, conoces la localidad, la historia, como os decía antes, pero esto se me quita del disco duro cuando te surgen necesidades, ¿sabes?... A mí donde me gusta vivir es aquí, pero la necesidad es la necesidad." (E.2, hombre, 51 años).

"Me gusta mi pueblo y mientras pueda pues yo viviré en mi pueblo, si no hubiera otro remedio, pues me tendría que ir. Pero, vamos, yo soy nativo de aquí y mientras pueda seguiré siendo, siempre que pueda tener trabajo aquí claro" (E.4, hombre, 46 años).

No obstante, las mismas personas entrevistadas también muestran un lado cambiante de la realidad rural, que puede tener relación con las nuevas iniciativas de gobernanza local. 
"En los últimos tiempos lo que se está viendo es que están llegando empresas transformadoras de leche y que están creando otros tipos de puestos de trabajo, para mujeres, para jóvenes y demás [en contraste con la agricultura tradicional masculinizada]. Ahora mismo tenemos aquí tres queserías importantes... habéis visto también una fábrica de leche que hay... luego, hay otra fábrica de quesos y fábrica de piensos que están haciendo nue$v a$, bueno, se ve actividad económica." (E.4, hombre, 46 años).

Así, dependiendo mucho de la realidad personal y del entorno social, algunos muestran una postura más optimista acerca de las posibilidades existentes en el propio medio rural. Ello lleva a cuestionar el extendido discurso de que la falta de empleo sea la causa principal de la despoblación, cuando bien puede ser uno más de sus efectos.

"No he tenido la necesidad de irme fuera, yo siempre he visto posibilidades de estar aquí, y estar haciendo cosas, y a los hechos, como dicen, me remito, que siempre estoy trabajando, incluso últimamente más de la cuenta" (E.3, mujer, 51 años).

En los discursos, los aspectos biofísicos del lugar se interrelacionan con los procesos subjetivos en la construcción de los significados de lugar. La cercanía con la naturaleza y con las personas, pero también las limitaciones y oportunidades sociolaborales se manifiestan de formas contradictorias. Hay ilusión y apego, pero también hay limitaciones y cierto recelo de las miradas urbanas prejuiciosas. Cabe destacar que en todas las entrevistas el territorio estudiado se presenta como un escenario deseable para las experiencias vitales diversas de las personas que están participando en esta iniciativa de gobernanza local con enfoque paisaje.

\subsubsection{Sentimiento de pertenencia}

Las entrevistas ponen de manifiesto que el debilitamiento de los vínculos socio-espaciales parece estar dificultando el arraigo de población en entornos rurales, aunque las valoraciones personales de las personas entrevistadas y los significados del lugar estén relacionados con una elección de quedarse en el medio rural. En ese sentido, y coincidiendo con estudios anteriores (Hidalgo y Hernández, 2001; Scannell y Gifford, 2014), los resultados muestran que cuando las personas se sienten vinculadas a su pueblo, reconocen y comparten ciertas señas de identidad y aprecian su entorno físico y social, eso genera un sentimiento de pertenencia que lleva al deseo por permanecer en ese entorno.
Los datos confirman que los vínculos familiares y las experiencias vividas en el medio rural se destacan en el proceso de arraigo y el desarrollo del sentimiento de pertenencia (Escalera, 2013).

"Lo primero que mi elección fue quedarme en el campo. Yo me hice cargo de la actividad de la agricultura de la explotación de mi madre una vez que ella se jubiló. Yo dije: pero si a mí esto me gustaba, yo, a mí me encantaba. ¿Por qué, si yo tenía esto, iba a buscar otra cosa?" (E.3, mujer, 51 años).

"Yo creo que los vínculos ayudan. Quiero decir, para que una persona se vaya a vivir al medio rural, si viene de una cultura rural eso ayuda, si tienes a tu familia que ha vivido alli, a tus padres, a tus abuelos..." (E.5, mujer, 38 años).

Así, la dimensión social del apego se revela como máximo exponente de pertenencia y vinculación con el lugar, pero no solo para los oriundos del medio rural, sino también para los nuevos residentes. Las relaciones sociales promueven el desarrollo del sentimiento de pertenencia, puesto que pertenecer a un determinado lugar implica, a su vez, formar parte de un grupo de personas con las que hay un proceso de identificación social (Cruz, 2006).

"A nivel personal, el hecho de pertenecer a un pueblo es pertenecer a un grupo de personas que es conocida y tienes afinidad. Tú sales en Palencia y no conoces a la gente por la calle, pero tú vas a un pueblo y te conoce todo el mundo. Conoces a todo el mundo, te puedes parar a hablar o no, tienes tu grupo de amigos con el que compartes aficiones, compartes muchas cosas"

(E.8, hombre, 39 años).

"Yo me considero mujer de pueblo a pesar de haber nacido en capital, desde chiquitita yo me he criado en la zona norte, zona de montaña, a mí la vida de pueblo me encanta" (E.1, mujer, 35 años).

En los resultados identificamos que las relaciones interpersonales constituyen una dimensión con entidad propia, que desarrollan y mantienen los significados del lugar, compartiendo y retroalimentando las valoraciones y, en su caso, las perspectivas de seguir vinculado y próximo al lugar de apego (Hernández, Hidalgo, Salazar-Laplace, y Hess, 2007). Así pues, el nivel social se encuentra relacionado con los lazos afectivos que se generan entre las personas de una comunidad, gracias a las interacciones que facilita ese lugar. Vidal et al. (2013) apoyan esta idea afirmando que la comunicación entre vecinos implica un modo de relacionarse con el entorno capaz de producir apego. Las personas entrevistadas otorgan a las relaciones sociales que mantienen en el entorno un papel 
central en la génesis y desarrollo de los vínculos afectivos con el lugar y el sentimiento de pertenencia. En este caso, la escasez de población y la preservación de una cultura más gregaria pueden estar favoreciendo el mantenimiento de relaciones de ayuda mutua.

"Entonces para mí eso es lo fundamental, el contacto con la gente [...] entonces eso, eso es vital, eso es vital, vital, o sea el apego, el contacto, el contacto con el pueblo, con la gente" (E.10, hombre, 49 años).

"Por muy pequeño que sea el pueblo tienes mucha más relación social aquí que en una gran ciudad [...] Y en ese núcleo de 40 personas, 40 amigos, yo no tengo habitualmente en la ciudad, aqui con cualquiera de ellos puedes crear relaciones." (E.7, hombre, 30 años).

Además, la posibilidad de desarrollar vínculos emocionales con las personas de la comunidad se ve facilitada por las características del entorno, a través de la satisfacción de necesidades, objetivos y metas de sus habitantes (Scannell y Gifford, 2010) y de las vivencias placenteras que proporcionan (Hidalgo, 1998). Esta vinculación puede estar relacionada con los significados otorgados por las personas a un espacio material y físicamente disponible para ellas (Vidal y Pol, 2005).

"El tema social... el hecho de que nos conozcamos todos, eso es muy importante. Yo, para mí eso. Y luego, hay otra cuestión, que yo paseo por este río que es mucho más feo que, yo que sé, los arribes del Duero, y ivamos! Yo aquí me lo paso pipa. Me lo paso pipa, porque yo conozco el terreno" (E.4, hombre, 46 años).

"Es todo como muy familiar, vivir en pueblo al final es familiar [...] Yo creo que en los pueblos sigue quedando muy buena gente todavía, y no sé, igual es el necesitar unos de otros muchas veces el que haga que la gente sea más acogedora o puedas hablar con cualquiera." (E.3, mujer, 51 años).

En el sentido opuesto, en estas relaciones tan cercanas también se encuentra el origen de muchos conflictos, ya que la confianza y conocimiento entre las personas lleva en algunas ocasiones a traspasar las barreras de la privacidad. Puede parecer contradictorio, sin embargo, más bien es complejo y constituyen dos caras de la realidad rural. Mientras lo más valorado es la cercanía social, también aparece el control social y la invasión de la privacidad como contrapunto. Ello puede ayudar a no caer en una caracterización idílica.

"El inconveniente más importante es que en un pueblo nos conocemos todos, y nos conocemos demasiado de bien y entramos, o nos gusta entrar, en la vida de los demás. Entonces, esa falta de intimidad eso es lo malo de los pueblos" (E.4, hombre, 46 años).

Así, observamos cómo los mismos procesos entrañan cercanía y ayuda mutua, pero a la vez pertenecer a una comunidad puede amenazar a la privacidad, que es tan valorizada y preservada en el actual modelo de vida posindustrial. En el equilibrio puede estar la clave para el deseo de pertenencia e identificación con el lugar.

\subsection{Participación y vínculo con el lugar}

La vinculación con el lugar también se encuentra relacionada con la participación de las personas en la transformación de su comunidad. Como han puesto de manifiesto diversos autores (Pol, 1996; Vidal et al., 2013), a través de la participación las personas dotan de significado a los lugares, significados que, además, atribuyen a su propia identidad personal y social. Los significados que se reflejan en el discurso de las personas entrevistadas en este estudio, revelan que existe relación entre su participación en la creación de la iniciativa Bosque Modelo Palencia y su vinculación con ese territorio concreto.

Los resultados indican que al participar de actividades con el propósito de solucionar los problemas colectivos que afectan al territorio en su conjunto, más allá de los límites de cada pueblo o municipio, las personas van construyendo vínculos entre sí y refuerzan mutuamente su capacidad de agencia para la transformación del lugar, lo que forma parte del proceso de apropiación del espacio (Pol, 1996; Vidal y Pol, 2005). Del análisis de las entrevistas emergieron dentro de la categoría 'participación y vínculo con el lugar' dos subcategorías sustantivas - dinamización del territorio y reconocimiento de una comarca. Como explicamos a continuación, parecen ayudarnos a comprender cómo el proceso de participación en una iniciativa de gobernanza local con enfoque paisaje puede estar incidiendo en los vínculos afectivos con el lugar.

\subsubsection{Dinamización del territorio}

La actuación sobre el territorio donde se ha generado la Iniciativa Bosque Modelo Palencia, tal como se recoge en su Plan estratégico (Bosque Modelo Palencia, 2017), tiene entre sus objetivos articular un tejido social fuerte, capaz de participar o al menos incidir en 
la gestión de los recursos disponibles en el entorno inmediato para impulsar el desarrollo sostenible de las localidades de la zona, tratando de paliar las devastadoras consecuencias de la despoblación. En los discursos analizados destaca la dinamización del territorio como una necesidad para la sostenibilidad, así como aparece una identificación personal con las metas planteadas de enfoque paisaje. Se identifica el Bosque Modelo Palencia como un posible espacio de revitalización del territorio y una iniciativa con la cual comprometerse para el desarrollo de escenarios deseables, fortaleciendo la vinculación con el territorio a través de las interacciones sociales en el marco de la participación en los procesos colectivos.

"Hay muchas otras cosas que se pueden hacer. Entonces, el territorio y el BM me parece un lugar que reúne todas las condiciones para poder hacer algo que verdaderamente fije población, genere dinero y encima sea de forma adecuada con el medio ambiente y que lo mejore." (E.9, hombre, 42 años).

"Hay que movilizar las personas, el territorio tiene muchísimos recursos, no hay más que verlo, si es que tienen de todo, pero esos recursos no son nada sin personas y sin personas productivas, pues eso es en lo que hay que centrarse, en las personas" (E.5, mujer, 38 años).

Se parte de un sentimiento y una percepción social de que los pueblos se apagan, se están muriendo junto con las personas mayores y con los jóvenes que se marchan cada año. Durante los últimos años, se está viendo cómo la población de los pueblos disminuye año tras año. Para muchos parece que el abandono del medio rural es inevitable. Además, hoy se evidencian dinámicas que tienden a producir más inmovilismo social.

"Al haber menos gente en los pueblos, lo que pasa es que hay menos actividad económica. Los pueblos se quedan desiertos y no hay nada, la gente es más mayor. La mentalidad de las personas mayores es diferente, tienen una mentalidad de que el que manda en casa es el señor mayor. Con lo cual, a los jóvenes, pues, no les dejan participar de ninguna manera y no les queda más remedio o que estar con la cabeza bajada sin poder desarrollar nada, ni poder mover la economía, o emigrar. iEso es así! [...] Y luego, a parte, que nos encontramos con muchos pueblos que, aparte de haber una densidad de $5 \mathrm{hab} . / \mathrm{km}^{2}$, el más joven tiene 55 años. Que es que esa es otra, el más joven es de 55 y hay pueblos que igual están viviendo 40 personas o 30 personas y, de 30 personas, hay 20 con más de 70 años. Entonces, eso es lo que es, eso es lo que es, y imilagros los justos! (E.4. hombre, 46 años).

Sin embargo, frente a esa realidad, para las personas entrevistadas la perspectiva es la de que hay que hacer algo. La dinamización del territorio aparece como una clave de esperanza, de que hay que inyectar energía y dinamizar el contexto social y económico del medio rural. Nos dicen que creen en que es posible crear una realidad que invite a venir y a quedarse "para ser feliz".

"Sí que el ver cómo que se están hundiendo esos pueblos, pues sí que me genera ganas de hacer cosas... En este sentido, si que es intentar ayudar y poner el granito de arena para intentar que sujetarlos un poco, que no se desangren como lo están haciendo" (E.8, hombre, 39 años).

"Yo trabajo porque esto sea así. Mi perspectiva es que no quiero que los pueblos se mueran. $Y$ entiendo que la gente puede venir a trabajar aquí, hay que tener los argumentos para que la gente quiera. Igual que la gente se ha ido para estudiar, para buscar un puesto de trabajo, pues ahora, digamos, que consiga hacer lo necesario para poder venir a vivir al pueblo y ser feliz aquí, claro" (E.15, hombre, 42 años).

Las referencias a la actividad y al movimiento aparecen en el discurso como motivos de su vinculación personal a iniciativas para promover la sostenibilidad del territorio.

"Yo, lógicamente, cualquier iniciativa [como el Bosque Modelo] que se ponga en marcha o que se intente poner en marcha para que sea un desarrollo, sirva como un desarrollo o un potenciador de la zona, yo soy el primero, o sea, iyo soy el primero!" (E.4, hombre, 46 años).

"Te mueve las ganas de trabajar, las ganas de esa ilusión de que haya algo, eso es lo que te mueve, es el esfuerzo. Que a ti no te importa el esfuerzo para que haya algo, el esfuerzo físico y económico. Porque al final, tú tiras de tu teléfono, no te creas que tengo yo el teléfono que es de [asociación]. Que yo, mi teléfono me le pago yo, mis kilómetros van a cuenta mía... para que esto salga adelante." (E.3, mujer, 51 años)

En ese esfuerzo por generar dinamismo se está promoviendo la innovación social, con la creación y participación en colectivos que buscan resolver los problemas locales con fórmulas creativas (Bock, 2016; Esparcia, 2014; Neumeier, 2012 y 2017). Las personas entrevistadas muestran cómo se generan iniciativas emprendedoras, a partir de la dinamización social, la cooperación y la revalorización del medio rural como estrategias para frenar la pérdida de capital humano, otorgando un papel fundamental a la vinculación entre las personas y de estas con el entorno.

"Pues el pueblo es un pueblo pequeñito. Tiene como pues en invierno [hace cuentas...], igual viven 40 personas. Eh, lo que pasa que es un pueblo peculiar, porque sí que hay muchas iniciativas y las hay, tanto empresa- 
riales como culturales... hay un centro social que la gente se mueve mucho. También hay..., por ejemplo, hay una fábrica de procesado de setas y otros productos, vamos, de la zona. Bueno, pues, también hay invernaderos de setas. Yo también tengo una, con otros socios, una granja de caracoles, por ejemplo. O sea que, hay, para ser un pueblo pequeño, si que hay bastantes iniciativas o hay cosillas que se mueven. Que somos pocos, pero bueno... También tenemos, por ejemplo, hemos hecho una empresa de explotación de paneles solares, en la bolera del pueblo. Es una empresa, que somos como treinta y pico socios, todos muy pequeños accionistas, pues uno $1000 €$, otro $2000 €$, y con eso tenemos una empresa. Bueno, pues nos da ahí una pequeña rentabilidad, que más que por la rentabilidad, pues eso, nos hace que nos juntemos un día al año, hablamos de los paneles, y bueno pues son cosas que se... pues, que hacen que tengas más relación y bueno en el pueblo pueda haber cosas que te animen a ir..." (E.8, hombre, 39 años).

Los resultados también muestran que, tal como afirman diversos autores ( Berroeta et al., 2015; Davies, 2001; Horlings, 2016; Manzo y Perkins, 2006), la existencia de conexión emocional entre las personas y los lugares implica un mayor compromiso en la puesta en marcha de proyectos destinados a mejorar el entorno en el que habitan.

"Hay una cosa que hay que potenciar y que veo que es la diferencia que ocurre en otros territorios como, por ejemplo, bueno, en este caso Navarra es un sitio, la Rioja, el País Vasco, a lo mejor también Valencia, Cataluña, en el que esto hay como un amor por tu territorio y unas ganas de generar algo en tu territorio, que hace que mucha gente se quede y hace empresas ahi." (E.9, hombre, 42 años).

"Yo es que me quedo como sea y quiero formar parte de la comunidad rural y vamos... intento invertir lo menos posible en una ciudad, porque para mí lo considero que no, que no quiero generar nada, que todo lo que quiera generar de mi actividad, o económica o intelectual, pues lo quiero dedicar a mi pueblo o a los pueblos" (E.10, hombre, 49 años).

De la misma manera, el establecimiento de vínculos afectivos con el pueblo, es decir, la existencia de apego, implica la tendencia a procurar mantener cierto grado de proximidad con el territorio (Hidalgo, 1998). Además, las iniciativas y esfuerzos de dinamización del territorio están generando una valoración más positiva del entorno rural y de ese lugar en particular. Se comparte en los grupos la necesidad de construir y socializar significados que faciliten la vinculación de los locales y que atraigan a nuevos residentes.

"No solo se trata de que haya temas laborales, digamos de alguna forma, si no que haya ciertas iniciativas o ciertos vínculos que te hagan atractivo el ir a los pueblos." (E.8, hombre, 39 años).

"Hay que borrar, es decir, hay que superar ese discurso de que hay que ir a la ciudad para ser feliz, para trabajar, para tener una buena vida... que es un discurso muy rural, pero que yo entiendo que se debería haber terminado ya, es un discurso agotado... ieh! No por tener una carrera, no por estar más preparado y por pagar una hipoteca en la ciudad, no por eso eres más feliz. Y la gente se está dando cuenta de eso" (E.15, hombre, 42 años).

En ese planteamiento esperanzador de dinamización del medio rural las nuevas tecnologías, la movilidad y las telecomunicaciones cobran un papel destacado como condiciones de posibilidad para el arraigo y la sostenibilidad. El modelo de vida rural deseable actualmente depende de estar interconectado al nivel global. Ya no se concibe la vida cotidiana en el medio rural estando las personas aisladas en sus respectivos pueblos. Ello es una parte importante del proceso de construcción de los nuevos paisajes culturales y socioambientales (Angelstam et al. 2013a; Angelstam et al., 2019a).

"Yo creo que en medio rural se puede vivir éticamente, solidariamente y en un modo moderno construyendo un estilo de vida coherente con lo que uno piensa. Al menos, igual que en una ciudad. A mí en este momento me lo parece, fundamentalmente gracias a las telecomunicaciones. Quiero decir, que sin acceso a internet esto no sería posible... El hecho de que yo pueda tener una reunión con vosotras on-line, y que yo ayer pidiera a XXX un libro y me lo hayan traído hoy por mensajería, pues de repente esto genera como un nuevo momento en los pueblos, que yo creo que lo podemos aprovechar" (E.15, hombre, 42 años).

"La naturaleza la tienes mucho más cerca, la frescura de los pueblos, eso sí. $Y$ desventaja, que muchas veces te tienes que desplazar para muchas cosas, pero bueno, gracias al maravilloso mundo de Internet te puedes facilitar muchas cosas..." (E.5, mujer, 38 años).

Aunque con optimismo y mostrando lo positivo del medio rural, otras entrevistas nos sitúan en las dificultades encontradas en las telecomunicaciones rurales. Claramente, nos hablan de la discriminación en los servicios que se prestan en los pueblos en materia de conectividad.

“...Habiendo tecnología, porque si no, no puedes vivir en el pueblo ... Aquí, por ejemplo, la tecnología regular. El móvil bien, pero internet pues bastante fatal. Pero bueno, el móvil funciona mucho mejor que internet, o sea, el internet del móvil, porque no tenemos ADSL ni cosas de esas. Nos llega cobertura $3 G$ en internet y gra- 
cias, y caro, muy caro [...] Ahora, uso el móvil de router y me va estupendamente. Lo de la tecnología, al final, lo mismo, te adaptas a lo que vas teniendo. Que te sirve, bien, que no te sirve, pues ya llegará, sé paciente. Hay otra gente que no, también, pues vienen de la ciudad, es que aquí no funciona, es que aquí... Ya, bueno, pues es que tenéis la suerte que ahí tenéis de todo bien. Aquí tenemos otras cosas. Yo vendo la tranquilidad, vamos, absoluta, como parte prioritaria del pueblo y que no se acabe, porque si todo fuera igual, a ver dónde íbamos a estar un poco relajados" (E.6, mujer, 36 años).

En cualquier caso, la alusión a Internet aparece en seis de las 16 entrevistas realizadas y se muestra como una cuestión importante en la nueva ruralidad - seguramente, aparecería más veces si las entrevistas se hubiesen realizado durante o después de la crisis sanitaria del coronavirus. Varios actores sociales mencionan el tema como una puerta a la esperanza para la dinamización de los territorios rurales.

"La sociedad rural se ha preparado para que todo el mundo diese el salto a vivir en la ciudad, pero no tenemos un plan de retorno. No tenemos un plan de retorno de decir, si eso no funciona, cómo vamos a hacerlo para que la gente que está en la ciudad y quiera vivir en un pueblo pueda hacerlo... Pues puede haber un plan... O sea, la mayor parte de los puestos a día de hoy cualificados se pueden hacer desde un ordenador, si lo puedes hacer desde un ordenador en una oficina en Palencia, lo puedes hacerlos desde un ordenador en una oficina en Acera de la vega, o en Celadilla o en... Entonces, no hay inconveniente, pero hay que decir que se puede, o sea, tenemos que decir que se puede. Si no lo decimos, no nos lo vamos a creer... Y lo cierto es que se puede, yo soy un ejemplo de que se puede" (E.15, hombre, 42 años).

\subsubsection{Reconocimiento de una comarca}

Otra categoría de significados que aparece relacionada a la puesta en marcha de la iniciativa Bosque Modelo Palencia es la necesidad de crear un sentimiento de comarca. Establecer un lugar dotado de significados compartidos que permita la identificación con un territorio amplio, capaz de dar respuestas a las necesidades sociales y personales, se presenta como una cuestión fundamental para la dinamización del medio rural. En la definición del ámbito territorial se evidencia la necesidad de generar apego hacia un territorio más allá de los límites del pueblo o de un municipio. En un contexto regional como Castilla y León, caracterizado por un gran número de pueblos y municipios de dimensiones muy reducidas, que dificultan la gestión de estrategias con una perspectiva holística de la sostenibilidad, la vida rural cotidiana ya se desarrolla en un espacio geográfico que supera los límites municipales.

"...Dependemos mucho de las telecomunicaciones y del coche. Estando en esa sintonía. yo creo que se puede hacer un proyecto de vida interesante en el medio rural, pero... encerrado en el pueblo. iNo!, no es la unidad ya el pueblo, no da de sí para eso, ni siquiera una cabecera de comarca, quiero decir... (E.15, hombre, 42 años).

Se percibe en las entrevistas que el enfoque paisaje para la construcción de una identidad más fuerte al nivel supramunicipal podría facilitar el arraigo de la población local y de nuevos residentes. Cuando se refieren a la puesta en marcha de nuevos proyectos parece importante que no se limiten al espacio de cada pueblo, sino proyectos comunes, que tengan como objetivo el desarrollo sostenible entre los pueblos.

"De lo que se trata yo creo es de que una comarca, un territorio, llamémoslo, por ejemplo, esto del Bosque Modelo, pues que, de alguna forma, en cualquier punto surjan iniciativas y actividades [...] El hecho de que haya movimiento en un territorio va a beneficiar a todos." (E.8, hombre, 39 años).

"Conocer el resto de pueblos y las gentes que viven en ellos para tener personas con quien establecer relaciones sociales. Conocer otros pueblos y sus actividades para tener una oferta cultural mayor..." (E.13, mujer, 25 años).

Asimismo, el conocimiento entre las personas del territorio y la transformación de la organización social hacia modelos más participativos y cooperativos favorecerían, según las personas entrevistadas, la puesta en marcha de acciones destinadas a paliar las carencias y solucionar los problemas de las pequeñas localidades en el territorio.

"Lo que hay es sentimiento de comarca porque nosotros sabemos, los que vivimos en XXXX (cabecera de comarca), sabemos que dependemos de los pueblos, y los pueblos dependen de nosotros para hacer esos servicios, no. Entonces tenemos como muy implantado lo que es la comarca, o sea, nos consideramos comarca" (E.4, hombre, 46 años).

"El hecho de que la gente, conozca a otra gente de otro sitio, que está más o menos cerca, pues te puede generar ese apego y puedas ayudar o puedas desarrollar allí iniciativas que, de otra manera, pues ni conoces, ni tienes intención de llevar a cabo." (E.8, hombre, 39 años).

Sin embargo, existe cierta tendencia a mantener una identidad localista que dificulta la puesta en marcha de iniciativas de carácter supralocal. Las diferencias históricas, culturales y en la actividad económica, 
entre los pueblos vecinos y entre las comarcas naturales que conforman la iniciativa Bosque Modelo Palencia, influyen en la construcción de las identidades territoriales, así como, en las diferentes necesidades a las que se enfrentan sus habitantes.

"Yo creo que apego hay, lo que pasa que el apego que hay ahora mismo es más..., demasiado cerrado. O sea, la gente tiene mucho apego a su pueblo, y el pueblo que está a un kilómetro le da más o menos igual" (E.8, hombre, 39 años).

"Hay zonas que no tienen nada que ver. Si estamos hablando de zonas del norte [...], no tenemos nada, pero es que no, en el carácter no tiene la gente nada que ver. Aquí en el valle [...] hay una unión brutal, o sea, me da igual desde [tal] hasta [cual], todos somos del valle XXXX" (E.7, hombre, 30 años).

Estos testimonios dejan entrever que no existe una identidad de lugar uniforme que abarque a todo el territorio de la iniciativa Bosque Modelo Palencia y manifiestan la necesidad de generar un sentimiento de pertenencia más amplio que impulse la vinculación socio-espacial en el ámbito de la iniciativa.

"He conocido a personas de otras comarcas y a raíz de realizar diversos encuentros podría decirse que hemos generado un grupo de personas itinerantes, dispuestas a crear vínculos en diferentes territorios y también a preservar y revalorizar esa identidad colectiva de 'soy de pueblo' haciendo actividades que hasta ahora no se estaban llevando a cabo en nuestros pueblos" (E.11, mujer, 31 años).

En contraposición a esa manifiesta fragmentación del territorio vivido y tradicionalmente experimentado, se está viendo cómo, según las personas entrevistadas, se van superando incluso conflictos locales con la puesta en marcha de iniciativas colectivas, tales como el Bosque Modelo Palencia, que se organizan a partir de procesos de participación y toma de decisiones en la búsqueda de soluciones de gestión a problemas comunes que afectan a territorios amplios.

"Yo he visto grandes avances significativos en lo que tiene que ver con deshacer los viejos conflictos que bloquean todo en los pueblos pequeños. Yo no sé si eso luego tiene una consecuencia directa sobre el desarrollo, pero sí que parece relevante que en un pueblo donde hay gente que hasta ahora no se hablaba, tu generes plataformas donde se vuelvan a encontrar, se naturalice eso y se vayan perdonando un poco los viejos desencuentros" (E.15, hombre, 42 años).

Los resultados muestran que se encuentra un sentido de reconocimiento de la comarca y de construc- ción del apego al lugar a través de plataformas de gobernanza local con enfoque paisaje, que favorecen la construcción de espacios sociales y comunitarios más amplios para crear sinergias y buscar soluciones a problemas comunes y también específicos.

"Sin duda, la unión hace la fuerza, y creo que si estamos todos y todas juntas conseguiremos que nuestros pueblos no desaparezcan. Juntando todas las experiencias de cada persona y con su pueblo, podremos lograr un conocimiento mayor de lo que sucede en nuestros pueblos" (E.12, hombre, 26 años).

"La gente que está tejiendo redes, lo está tejiendo siempre en un carácter como más global, en un pueblo no, pero bueno, en ese carácter comarcal, si'" (E.15, hombre, 42 años).

El discurso compartido entre las personas implicadas en la iniciativa Bosque Modelo Palencia es esperanzador. Seguramente, muchos otros habitantes del medio rural podrían mostrar perspectivas muy distintas y mucho menos positivas sobre el futuro del territorio. Sin embargo, este estudio ha intentado capturar precisamente aquellos significados que ayuden a comprender qué mueve a las personas que participan en iniciativas colectivas a comprometerse de esa manera y cómo ello puede incidir en el apego al lugar y en la decisión de vivir en los territorios rurales.

\section{CONCLUSIONES}

Los fenómenos de despoblación rural están cada vez más presentes en los debates públicos de los últimos años. Parecen preocupar las consecuencias ambientales y económicas del cambio climático que amenaza a la sostenibilidad de los sistemas socioecológicos y que se vienen relacionando con el abandono del medio rural y la excesiva concentración de población en las grandes ciudades. En las últimas décadas, han surgido iniciativas de gobernanza local con estructuras multisectoriales y multinivel, implicando la creación de redes entre agentes sociales locales, pero, al mismo tiempo, articuladas con organismos de ámbito provincial, regional, nacional e internacional. Este planteamiento, denominado 'enfoque paisaje', pone el énfasis en la participación de las personas y de las comunidades en la gestión y utilización de los recursos naturales de su territorio y en la promoción de la sostenibilidad en todas sus dimensiones.

Asumiendo la subjetividad como una dimensión fundamental de la sostenibilidad, a partir de un es- 
tudio de caso de la iniciativa Bosque Modelo Palencia, en el centro-norte de Castilla y León, analizamos la vinculación socioespacial en personas altamente implicadas en promover procesos de gobernanza local con enfoque paisaje en ese territorio. Así, partiendo de constructos teóricos como apego al lugar, apropiación del espacio e identidad de lugar, se ha desarrollado una investigación cualitativa con entrevistas en profundidad semiestructuradas para explorar los significados construidos y compartidos socialmente sobre el medio rural. Analizamos cómo la participación en iniciativas colectivas que procuran promover la sostenibilidad puede incidir en su vinculación socioafectiva con ese lugar.

Estudios anteriores realizados desde la psicología ambiental, principalmente en contextos urbanos, mostraron que las personas que desarrollan el apego por un determinado lugar manifiestan el deseo de permanecer en ese lugar. Además, concluyeron que los lugares adquieren significados que pasan a formar parte de las propias identidades en la medida en que las personas tienen posibilidad de acción sobre los espacios y pueden implicarse en su transformación. En este estudio de caso analizamos de qué manera las iniciativas de gobernanza local con enfoque paisaje pueden ofrecer ese espacio de acción colectiva para la trasformación de los territorios rurales en espacios vinculantes y lugares de apego. Se intenta así comprender cómo la existencia de lazos emocionales con el medio rural está influyendo en la decisión personal de continuar en ese territorio, mientras otros elementos pueden estar contribuyendo a la despoblación del medio rural.

A partir del análisis realizado de las entrevistas emergieron de manera destacada, teniendo en cuenta los objetivos de la investigación, dos categorías temáticas principales, estando cada una compuesta por otras dos subcategorías sustantivas. La primera categoría principal se denominó "referencias de identidad de lugar" e incluye dos subcategorías: significado de lugar y sentimiento de pertenencia. A su vez, la segunda categoría se denominó "participación y vínculo con el lugar", incluyendo dos subcategorías: dinamización del territorio y reconocimiento de una comarca.

Los resultados encontrados indican que los significados de lugar recogen las vivencias emocionales, promoviendo o dificultando el sentimiento de pertenencia y el desarrollo del apego al lugar. Hay una percepción de infravaloración del medio rural y de sus habitantes por parte de la población urbana, pero los discursos nos muestran que las personas implicadas en los procesos de gobernanza local con enfoque paisaje, en el caso de estudio del Bosque Modelo Palencia, comparten significados positivos asociados a la ruralidad y una alta apreciación de su entorno próximo.

Las relaciones sociales y familiares aparecen de manera destacada en el desarrollo del sentimiento de pertenencia, así como las características del entorno natural y el contacto con la naturaleza. La cercanía es una característica que las personas entrevistadas utilizan para retratar la realidad de los pueblos, tanto en el sentido físico, de proximidad con la naturaleza y los lugares apreciados, como social, en cuanto a relaciones sociales de calidad. Pero, algunas veces, la cercanía es percibida como una amenaza a la privacidad. Por tanto, el equilibrio entre la cercanía y la privacidad parece ser clave de cara a la satisfacción en la vida cotidiana en los contextos rurales y para el fortalecimiento del sentimiento de pertenencia.

Por otro lado, la dinamización del territorio aparece como una necesidad para la calidad de vida y en la lucha contra la despoblación del medio rural. Los significados atribuidos a la dinamización del territorio hacen referencia, principalmente, al fortalecimiento del tejido social y a las redes locales como un motor para crear condiciones de dinamización económica. Se entiende la dinamización del territorio como la construcción de dinámicas sociales y de promoción de proyectos dentro de un marco colectivo de acción supralocal. En ese sentido, emergen también los significados asociados al reconocimiento de una comarca como unidad de intervención en la gobernanza local, pero también de realidad de vida cotidiana que supera con mucho los límites de los pueblos y municipios. La comarca y el territorio amplio posibilitan, según los resultados, la creación de un sentimiento de pertenencia supralocal, que se presenta como un mecanismo fundamental para la dinamización de los pueblos y para generar apego hacia un territorio más amplio, que sea capaz de satisfacer necesidades diversas. Se comparte la idea de que la puesta en marcha de proyectos con enfoque paisaje, que tengan como objetivo la sostenibilidad socioambiental de los territorios rurales, facilita el arraigo de la población local y de nuevos residentes.

Del estudio se puede concluir que hay relación entre la participación en iniciativas de gobernanza local con enfoque paisaje y una fuerte vinculación de las personas participantes con el territorio estudiado. Sin 
embargo, nuevos estudios son necesarios para ampliar y profundizar en los significados analizados y, sobre todo, resta por investigar si el apego al lugar que manifiestan las personas participantes en la investigación puede ser un resultado de su implicación en las iniciativas colectiva o, por otro lado, es precisamente un factor previo que les lleva a comprometerse con las iniciativas en ese territorio vivido. Seguramente nos encontremos ante un proceso de retroalimentación sobre el que hay que seguir indagando.

\section{REFERENCIAS BIBLIOGRÁFICAS}

Alario Trigueros, M. y Baraja Rodríguez, E. (2006). Políticas Públicas de desarrollo rural en Castilla y León, ¿Sostenibilidad consciente o falta de opciones?: Leader II. Boletín de la Asociación de Geógrafos Españoles, 41, 267-294. Recuperado de https://bage.age-geografia.es/ojs/index.php/ bage/article/view/2000

Angelstam, P., Andersson, K., Annerstedt, M., Axelsson, R., Elbakidze, M., Garrido, P., Grahn, P., Jönsson, K. I., Pedersen, S., Schlyter, P., Skärbäck, E., Smith, M., y Stjernquist, I. (2013a). Solving problems in social-ecological systems: Definition, practice and barriers of transdisciplinary research. Ambio, 42(2), 254-265. doi: https://doi. org/10.1007/s13280-012-0372-4

Angelstam, P., M. Grodzynskyi, K. Andersson, R. Axelsson, M. Elbakidze, A. Khoroshev, I. Kruhlov y V. Naumov. (2013b). Measurement, collaborative learning and research for sustainable use of ecosystem services: Landscape concepts and Europe as laboratory. $A M B I O, 42(2), 129-145$. doi: https://doi.org/10.1007/s13280-012-0368-0.

Angelstam, P., Manton, M., Cruz, F., Fedoriak, M., y Pautov, Y. (2019a). Learning Landscape Approach Through Evaluation: Opportunities for Pan-European Long-Term Socio-Ecological Research. In Current Trends in Landscape Research. Innovations in Landscape Research (pp. 303-320). Springer. doi: https://doi.org/10.1007/978-3-03030069-2_12

\section{RECONOCIMIENTOS}

Agradecemos especialmente a las personas participantes de la investigación, que nos brindaron generosamente su tiempo y la disponibilidad para compartir sus experiencias. También, agradecemos sinceramente a los revisores del artículo por el minucioso trabajo que han realizado y que, sin lugar a dudas, ha mejorado la calidad del artículo que aquí se encuentra.

Este trabajo de investigación contó inicialmente con financiación en el marco del Proyecto Europeo de Investigación SIMWOOD - Sustainable Innovative Mobilisation of Wood, financiado en el 7th Framework Programme - KBBE, proyecto no 613762 .

Angelstam, P., Manton, M., Elbakidze, M., Sijtsma, F., Adamescu, M., Avni, N., Beja, P., Bezak, P., Zyablikova, I., Cruz, F., Bretagnolle, V., Díaz-Delgado, R., Ens, B., Fedoriak, M., Flaim, G., Gingrich, S., Lavi-Neeman, M., Medinets, S., Melecis, V., Muñoz-Rojas, J., Schäckermann, J., Stocker-Kiss, A., Setälä, H., Stryamets, N., Taka, M., Tallec, G., Tappeiner, U., Törnblom, J., Yamelynets, T. (2019b). LTSER platforms as a place-based transdisciplinary research infrastructure: Learning landscape approach through evaluation. Landscape Ecology 34(7): 1461-1484. doi: https://doi.org/10.1007/ s10980-018-0737-6

Angelstam, P., R. Axelsson, M. Elbakidze, L. Laestadius, M. Lazdinis, M. Nordberg, I. Pătru-Stupariu, y M. Smith (2011). Knowledge production and learning for sustainable forest management on the ground: Pan-European landscapes as a time machine. Forestry, 84(5), 581-596. doi: https://doi. org/10.1093/forestry/cpr048

Arabatzis, G., Aggelopoulos, S., y Tsiantikoudis, S. (2010). Rural development and LEADER + in Greece: Evaluation of local action groups. Journal of Food, Agriculture and Environment, 8(1), 302-307. https://www.wflpublisher.com/Abstract/1512

Axelsson, R. (2009). Landscape Approach for Sustainable Development: From Applied Research to Transdisciplinary Knowledge Production. Tesis doctoral, Swedish University of Agricultural Sciences, Uppsala. Recuperado de https://pub.epsilon. slu.se/2174/ 
Axelsson, R., Angelstam, P., Elbakidze, M., Stryamets, N., y Johansson, K.-E. (2011). Sustainable Development and Sustainability : Landscape Approach as a Practical Interpretation of Principles and Implementation Concepts. Journal of Landscape Ecology, 4(3), 5-30. doi: https://doi.org/10.2478/ v10285-012-0040-1

Bailey, E., Devine-Wright, P., y Batel, S. (2016). Using a narrative approach to understand place attachments and responses to power line proposals: The importance of life-place trajectories. Journal of Environmental Psychology, 48 (April 2018), 200-211. doi: https://doi.org/10.1016/j. jenvp.2016.10.006

Berroeta, H., Ramoneda, Á., Rodríguez, V., Di Masso, A., y Vidal, T. (2015). Apego de lugar, identidad de lugar, sentido de comunidad y participación cívica en personas desplazadas de la ciudad de Chaitén. Magallania, 43 (3), 51-63. Recuperado de: https://scielo.conicyt.cl/pdf/magallania/ v43n3/art05.pdf

Berroeta, H., Vidal, T. y Di Masso, A. (2016). Usos y significados del espacio público comunitario. Interamerican Journal of Psychology, 50 (1), 75-85. Recuperado de: https://www.redalyc.org/pdf/ 284/28446021009.pdf

Bock, B. (2016). Rural marginalisation and the role of social innovation: a turn towards nexogenous development and rural reconnection. Sociologia Ruralis, 56 (4), 552-573. doi: https://doi.org/ 10.1111/soru.12119

Bosque Modelo Palencia (2017). Plan Estratégico del Bosque Modelo Palencia. Recuperado de: https:// palenciabosquemodelo.es/mision-y-vision/

Camarero, L.; Cruz, F.; González, M.; Pino, J. A.; Oliva, J.; Sampedro, G. (2009). La población rural de España. De los desequilibrios a la sostenibilidad social. Barcelona, España: Fundación Obra Social La Caixa.

CES (2012). Informe a Iniciativa Propia 1/2012 sobre Población y Poblamiento en Castilla y León. Valladolid, España: Consejo Económico y Social de Castilla y León.

Cruz, F. (2006). Género, psicología y desarrollo rural: La construcción de nuevas identidades. Madrid, España: Ministerio de Agricultura, Pesca y Alimentación.
Cruz, F. 2019. Bosque Modelo Palencia: Landscape Approach y redes para la sostenibilidad de los territorios rurales. Revista $\mathrm{PH}$ Instituto Andaluz del Patrimonio Histórico, 98: 276-286. doi: https://doi.org/10.33349/2019.98.4463

Cruz, F. et al. (2011). Desarrollo rural y sostenibilidad. Estrategias y experiencias en España y Brasil. Palencia, España: Asociación País Románico.

Davies, A. (2001). What silence knows - planning, public participation and environmental values. Environmental Values, 10(1), 77-102. doi: https:// doi.org/10.3197/096327101129340750

Di Masso, A., Dixon, J. y Durrheim, K. (2013) Place attachment as discursive practice. En: L.C. Manzo y P. Devine-Wright (eds), Place attachment: advances in theory, methods and applications (pp. 75-86). London, United Kingdon: Routledge.

Escalera, J. (2013). Amor a la tierra. Identidades colectivas y resiliencia de los socioecosistemas. En: Ruiz Ballesteros, E. y Solana Ruiz, J. L., Complejidad y Ciencias Sociales (pp. 333-376). Sevilla, España: Universidad Internacional de Andalucía.

Esparcia, J. (2003). Valoración y balance de LEADER II: La consolidación de un modelo. Actualidad LEADER, 21, 8-15. Recuperado de: http://miteco. gob.es/app/publicaciones/art_datos.asp?articulo id $=87 \&$ codrevista $=$ LEAD

Esparcia, J. (2014). Innovation and networks in rural areas. An analysis from European innovative projects. Journal of Rural Studies, 34, 1-14. doi: https://doi.org/10.1016/j.jrurstud.2013.12.004

FEMP (2017). Población y despoblación en España 2016: El 50\% de los municipios españoles, en riesgo de extinción. Documento de trabajo de la Comisión de Despoblación de la Federación Española de Municipios y Provincias. Recuperado de: http://femp.femp.es/files/566-2117-archivo/ 20170125\%20informe_despoblacion.pdf

Flick, U. (2004). Introducción a la investigación cualitativa. Madrid: Morata.

Grenni, S., Soini, K., y Horlings, L. G. (2019). The inner dimension of sustainability transformation: how sense of place and values can support sustainable place-shaping. Sustainability Science, 15, 411422. doi: https://doi.org/10.1007/s11625-01900743-3

Guattari, F. (1996). Las tres ecologías. Valencia: Pre-textos. 
Hernández, B., Hidalgo, M. C., Salazar-Laplace, M. E., y Hess, S. (2007). Place attachment and place identity in natives and non-natives. Journal of environmental psychology, 27(4), 310-319. https://doi.org/10.1016/j.jenvp.2007.06.003

Hidalgo, M. C., y Hernández, B. (2001). Place attachment: Conceptual and empirical questions. Journal of Environmental Psychology, 21(3), 273-281. doi: https://doi.org/10.1006/jevp.2001.0221

Hidalgo, M.C. (1998). Apego al lugar: ámbitos, dimensiones y estilos. Tesis doctoral. Tenerife: Universidad de la Laguna. Recuperado de: http://riull. ull.es/xmlui/handle/915/10067

Hidalgo, M.C. (2013) Operationalization of place attachment: A consensus proposal. Studies in Psychology, 34(3), 251-259. doi: https://doi. org/10.1174/021093913808295190

Horlings, L. G. (2016). Connecting people to place: Sustainable place-shaping practices as transformative power. Current Opinion in Environmental Sustainability, 20, 32-40. doi: https://doi. org/10.1016/j.cosust.2016.05.003

Huang R. (2016). RQDA: R-based Qualitative Data Analysis. R package version 0.2-8. Recuperado de: http://rqda.r-forge.r-project.org/.

IMFN - International Model Forest Network Secretariat (2008). Model Forest Development Guide. Natural Resources Canada - Canadian Forest Service, Ottawa, Canadá. Recuperado de: http://medland. ctfc.cat/official-documentation/documents/ Model\%20Forest\%20Development\%20Guide.pdf

Lewicka, M. (2011). Place attachment: How far have we come in the last 40 years? Journal of Environmental Psychology, 31(3), 207-230. doi: https:// doi.org/10.1016/j.jenvp.2010.10.001

Manzo, L. C., y Perkins, D. D. (2006). Finding common ground: The importance of place attachment to community participation and planning. Journal of Planning Literature, 20(4), 335-350. doi: https:// doi.org/10.1177/0885412205286160

Marcy, R. T. y Mumford, M. D. (2007). Social innovations: enhancing creative performance through causal analysis. Creativity Research Journal, 19, 123-140. doi: https://doi.org/10.1080/ 10400410701397180

Maurer, A. M. y Silva, T. N. (2014). Analytical Dimensions for Identifying Social Innovations: Evidence from Collective Enterprises. Brazilian Business
Review, 11(6), 127-50. doi: https://doi. org/10.15728/bbr.2014.11.6.6

Mendoza, C. y Bartolo Ruiz, D. (2012). Lugar, sentido de lugar y procesos migratorios. Migración internacional desde la periferia de la Ciudad de México. Documents d'Anàlisi Geogràfica, vol. 58(1), 51-77. doi: https://doi.org/10.5565/rev/dag.191

Morin, E. (1994). Introducción al pensamiento complejo. Barcelona: GEDISA.

Navarro Valverde, F. A., Cejudo García, E., y Maroto Martos, J. C. (2012). Aportaciones a la evaluación de los programas de desarrollo rural. Boletín de La Asociación de Geógrafos Españoles, (58), 349379. doi: https://doi.org/10.21138/bage.2071

Neumeier, S. (2012). Why do social innovations in rural development matter and should they be considered more seriously in rural development research? - Proposal for a stronger focus on social innovations in rural development research. Sociologia Ruralis, 52(1), 48-69. doi: https://doi. org/10.1111/j.1467-9523.2011.00553.x

Neumeier, S. (2017). Social innovation in rural development: identifying the key factors of success. Geographical Journal, 183(1), 34-46. doi: https:// doi.org/10.1111/geoj.12180.

Nieto Masot, A., y Cárdenas Alonso, G. (2015). El método Leader como política de desarrollo rural en Extremadura en los últimos 20 años (1991-2013). Boletín de la Asociación de Geógrafos Españoles, 69, 139-162. doi: https://doi.org/10.21138/ bage.1893

Pinto de Carvalho, L. y Cornejo, M. (2018). Por una aproximación crítica al apego al lugar: una revisión en contextos de vulneración del derecho a una vivienda adecuada. Athenea Digital, 18(3), e-2004. doi: https://doi.org/10.5565/rev/ athenea.2004

Pol, E. (1996) La apropiación del espacio. En Iñiguez, L y Pol, E (coords.) Cognición, representación y apropiación del espacio. Monografies Psico/Socio/Ambientals, 9, 45-21. Barcelona: Universitat de Barcelona. Recuperado de: http://www.ub. edu/escult/editions/Oapropia.pdf

Ramos de Robles, S. L., y Feria Cuevas, Y. (2016). La noción de sentido de lugar: una aproximación por medio de textos narrativos y fotografías. Innovación educativa, 16(71), 83-110. Recuperado de: 
https://dialnet.unirioja.es/servlet/ articulo?codigo $=5895681$

Ried Luci, A. (2015) La experiencia de ocio en la naturaleza como fundamento de la construcción de sentido del lugar: el caso del Parque Natural de Urkiola, Bizkaia, Euskadi, España. Revista de Geografía Norte Grande, 60, 215-237. doi: http:// dx.doi.org/10.4067/S0718-34022015000100012

Ried Luci, A., Le Bon, A., Lobo, S. C., y Henriquéz, R. S. (2018). Sentidos del lugar desde la experiencia de ocio y turismo en áreas silvestres protegidas: una metasíntesis. Pasos: Revista de Turismo y Patrimonio Cultural, 16(3)., pp. 701-716. doi: https://doi.org/10.25145/j.pasos.2018.16.050

Rodríguez-Chaves, A y Solís-Rosales, S. (2016). Turismo y Patrimonio cultural inmaterial: Alternativa de complementariedad para el desarrollo de los territorios rurales. Revista Espiga, 15(32), 169181. doi: https://doi.org/10.22458/re.v15i32. 1588

Scannell, L. y Gifford, R. (2010). Defining place attachment: A tripartite organizing framework. Journal of Environmental Psychology, 30(1), 1-10. https://doi.org/10.1016/j.jenvp.2009.09.006
Scannell, L., y Gifford, R. (2014). Comparing the theories of interpersonal and place attachment. En: L.C. Manzo y P. Devine-Wright (2013). Place attachment: Advances in theory, methods, and applications (pp. 23-36). London, United Kingdon: Routledge.

Stake, R.E. (2005). Investigación con estudio de casos. Madrid: Morata.

United Nations (2018). 2018 Revision of World Urbanization Prospects. Department of Economic and Social Affairs - Population Division. Recuperado de: https://population.un.org/wup/Publications/ Files/WUP2018-Report.pdf

Vidal, T., y Pol, E. (2005). La apropiación del espacio: Una propuesta teórica para comprender la vinculación entre las personas y los lugares. Anuario de Psicologia, 36(3), 281-297. Recuperado de: https:// www.raco.cat/index.php/AnuarioPsicologia/article/ view/61819

Vidal, T., Berroeta, H., di Masso, A., Valera, S., y Peró, M. (2013). Apego al lugar, identidad de lugar, sentido de comunidad y participación en un contexto de renovación urbana. Estudios de Psicología, 34(3), 275-286. doi: https://doi.org/ 10.1174/021093913808295172 